\title{
Fuentes de la Grammatica Hespanhola para uso dos Portugueses de Nicolau Peixoto (1848)
}

Sónia Duarte

\section{(2) OpenEdition}

Edición electrónica

URL: https://journals.openedition.org/dhfles/750

DOI: $10.4000 /$ dhfles.750

ISSN: 2221-4038

\section{Editor}

Société Internationale pour l'Histoire du Français Langue Étrangère ou Seconde

Edición impresa

Fecha de publicación: 1 junio 2009

Paginación: 164-184

ISSN: 0992-7654

Referencia electrónica

Sónia Duarte, «Fuentes de la Grammatica Hespanhola para uso dos Portugueses de Nicolau Peixoto (1848) », Documents pour l'histoire du français langue étrangère ou seconde [En ligne], 42 | 2009, mis en ligne le 16 janvier 2011, consulté le 14 juin 2021. URL : http://journals.openedition.org/dhfles/750 ; DOl : https://doi.org/10.4000/dhfles.750

Este documento fue generado automáticamente el 14 junio 2021.

(c) SIHFLES 


\title{
Fuentes de la Grammatica Hespanhola para uso dos Portugueses de Nicolau Peixoto (1848)
}

\author{
Sónia Duarte
}

\section{Nota preliminar}

1 Pese a que es en el siglo XIX cuando las reformas educativas en Europa conducen a la institucionalización de la enseñanza de lenguas vivas, en Portugal la introducción del Español en la enseñanza reglada sólo ocurre a inicios del siglo XX (Carvalho 1996), en lo que atañe a la enseñanza universitaria, y a finales del mismo siglo, en lo que concierne a la enseñanza básica y secundaria. Asimismo, aunque las primeras gramáticas para la enseñanza de lenguas extranjeras remontan al siglo XVI, como ya se ha demostrado (Messner 2003¹ ; Ponce de León 2005, $2006 a^{2}$ y 2007 ; Álvarez 2005 ; Salas 2005a), anteriormente a la obra en estudio, la tradición didacticográfica del español en Portugal es en rigor inexistente, salvo contadas aportaciones al estudio de la lengua española desde el ámbito lexicográfico ${ }^{3}$ y una única obra de carácter gramaticográfico (Moura 1821) ${ }^{4}$. Efectivamente, la gramática editada por Nicolau Peixoto en 1848 - y ampliada y revisada por su hijo (José Maria Borges da Costa Peixoto) diez años después - parece ser la primera gramática del español para portugueses.

2 No obstante esta laguna en la tradición anterior, la obra editada por los Peixoto, sea en el plano metodológico, sea en el lingüístico, toma como referencia a otros autores cuya huella se procurará rastrear en este estudio, aunque, para no extenderlo demasiado, se enfocará aquí solamente el plano lingüístico ${ }^{5}$.

\section{Datos biobibliográficos}

3 La información disponible sobre Nicolau Peixoto es reducida y, a veces, contradictoria. No se sabe su fecha de nacimiento y en cuanto a su origen, se dividen las opiniones 
entre Oporto (Domingo Garcia Peres 1890) y Vila Real (Silva 2001[1858-1923] ${ }^{6}$; Fonte 1998). Ya respecto de su experiencia profesional, los investigadores consultados(Silva 2001 y Fonte 1998) coinciden en que, antes de editar la obra en cuestión, Nicolau Peixoto había trabajado como alférez y escribano. João Barroso da Fonte refiere aun (1998 : 454) la participación del primer editor de la Grammatica en las luchas liberales e Inocêncio Silva (2001 [1858-1923], tomo VI : 269) da cuenta de que Peixoto trabajó como director de los celadores del ayuntamiento de Oporto. Ya Domingo Garcia Peres no aporta cualquier información sobre la actividad profesional de Peixoto. Para su muerte,Inocêncio Silva indica la fecha de 1862 y, según el mismo autor, éste es también el año en el que muere José Peixoto, respecto de quien, aparte de su fecha de nacimiento y muerte (1833-1862), poco más se sabe que el hecho de que ocupó una plaza de funcionario del Estado.

Los datos bibliográficos también presentan significativas lagunas. Tanto en Domingo García Peres (1890) como en Simão Cardoso (1994), se les asigna indistintamente a los Peixoto el conjunto de sus obras : la Grammatica Hespanhola para uso dos Portuguezes (Oporto 1848 y Lisboa $1858^{7}$ ) y la Guia da conversação Hespanhola para uso dos Portuguezes (Lisboa 1860). A estas obras, quizás haya que añadir los Diccionarios Hespanhol-Portugueze Portuguez-Hespanhol, anunciados en la contra-portada del texto de 1848 y en los anuncios de agosto de 1848, en el Defensor Diario, si bien, como pone de manifiesto Ponce de León $(2006 a ; 2007: 63)$, no hay constancia de que ese diccionario se haya publicado o siquiera terminado, o incluso de que su edición estuviera a cargo de los Peixoto. Sin embargo, la complementaridad entre estas obras (señalada también en Salas 2005b:2) apoya la tesis de Ponce de León $(2005: 677 ; 2006 a)$ en cuanto a la existencia de un " proyecto didáctico » constituido por la Grammatica, la Guia y, tal vez, los Diccionarios.

De acuerdo con el enfoque aquí asumido,conviene sobre todo subrayar que no queda claro el estatuto de Nicolau Peixoto en relación con la obra de la que aquí se trata. Tanto Inocêncio Silva, en su ya referido Diccionario, como Nicolau Peixoto, en la primera edición de su gramática, parecen diferenciar entre la identidad del autor y la del editor. Ya en la Guia, José Peixoto (1860) parece reivindicar la autoría de la Grammatica, aunque ello carece de verosimilitud, teniendo en cuenta que en 1848, José Peixoto tendría alrededor de 15 años. Pero más importante todavía parece ser puntualizar el concepto de 'autoría', identificándolo en esta obra con la recopilación de una tradición filtrada por medio del criterio de autoridad, como queda claro en la parte final del prólogo : " este estudo torna-se mais facil ainda pelo methodo, claridade e exactidão das regras e observações, que dos melhores autores se recopilaram [la cursiva es mía] na presente grammatica » (Peixoto $1848: 7$ ).

\section{Fuentes}

6 Es decir, no obstante ser consciente de la condición inaugural de su trabajo, como de una nota inicial se puede concluir ${ }^{8}$, Nicolau Peixoto subraya igualmente su deuda para

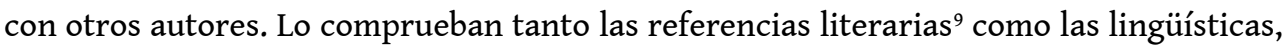
en las que ahondaremos a continuación. A veces, eso representa tan solo el reconocimiento de la deuda hacia los autores aludidos, otras, coincidencia con sus tesis y otras, todavía, disidencia. Entre esas fuentes con las que la Grammatica manifiesta identificación parece estar la Encyclopédie, ou Dictionnaire raisonné des sciences, des arts et 
des métiers de Diderot y d'Alembert - a la que aquí se presenta como garantía de ilustración y corrección de ideas ${ }^{10}$.

Otro caso con el que en la obra se asumen ciertas convergencias teóricas es la gramática inglesa de José de Urcullu, referida en el marco de la discusión sobre la importación lexical y de la que el texto se vale para criticar la opción por anglicismos y galicismoscuando exista un término castellano.Cabe resaltar la referencia a la obra de este exiliado de origen vasco (Silva 2001 [1858-1923], tomo V : 149), por motivos de índole tanto interna -el ámbito temático (la enseñanza de idiomas en Portugal)-, como externa -el paralelismo en el título (Grammatica Ingleza para uso dos Portuguezes), el lugar de edición (Oporto), la editora (Typographia Commercial) e incluso la fecha (1848). Éste es, por cierto, el único caso de transcripción textual. Aunque la edición citada es la de 1848, parece haber indicios de que Peixoto conocía igualmente la versión abreviada editada en Lisboa, en $1830^{11 .}$ Efectivamente, Peixoto adopta como epígrafe en su obra una cita de Carlos $\mathrm{V}$ que aparece también como epígrafe en la de Urcullu, aunque exclusivamente en la edición de 1830. Por supuesto, también es posible que Peixoto haya tomado la cita de otra fuente.

el contrario,se critica, en la Grammatica hespanhola de Peixoto, el Diccionario da Lingua Portugueza de António de Morais Silva (Lisboa 1789), por la adaptación a la fonética del portugués de un extranjerismo, sin que ello estuviera validado por el uso lingüístico ${ }^{12}$.

9 Una crítica similar va dirigida hacia las obras académicas. Por una parte, al Diccionario de la Academia (s.d.), por admitir terminaciones poco usadas en el caso de los numerales ordinales ${ }^{13}$; por otra parte, a la Grammatica de la Real Academia Española (Madrid 1796) ${ }^{14}$, por censurar el "leísmo" en contra de un uso generalizado y de la eufonía ${ }^{15}$. También se critica la GRAE por ausencia de exhaustividad, en cuanto a los monosílabos con tilde diacrítica ${ }^{16}$ y por no marcar como defectivo el verbo abolir ${ }^{17}$. La única nota positiva sobre la RAE está en el apoyo a sus reformas ortográficas ${ }^{18}$. En la obra de Peixoto, Urcullu aparece como soporte teórico, en defensa de criterios más prácticos (es decir, didácticos) y más populares, que observaban tanto la pronunciación, como el uso y la situación de aprendizaje ${ }^{19} \mathrm{~A}$ la luz de la información aportada por José Jesús Gómez Asencio (1981) puede que, entre las obras académicas, el texto tenga por referencia bien la Ortografía de 1826, bien el Prontuario de Ortografía de la Lengua Castellana, reeditado 30 veces a partir de 1828, bien ambas. El hecho de que la Academia privilegiara la pronunciación antes que la etimología y el uso no significa que, a raíz de un cambio de criterio que, según Esteve Serrano (2007), ocurre entre 1726 y 1741, no los considerara en el ámbito de lo que este autor denomina "jerarquía de valores determinada $»^{20}$, coincidiendo con el texto editado por Peixoto en esta forma de plantearlo. Muy distintos eran entonces, por cierto, los principios ortográficos predominantes en la Academia Portuguesa, según una cita de Urcullu ${ }^{21}$ en la Grammatica de Peixoto ${ }^{22}$, en la que se subraya que incluso los que, como Madureira (João de Moraes Madureira Feijó, se supone), defendían el criterio de la etimología tenían que tener en cuenta otros criterios. Entre los autores portugueses que, como el del texto en estudio, seguían el criterio de la pronunciación está Jerónimo Soares Barbosa (1822). A pesar de que apoya la simplificación ortográfica empreendida por la Academia, el texto de Peixoto, por razones de eficacia lingüística e índole expresiva y retórica, critica propuestas más radicales. Del mismo modo, también se presentan reservas con relación 
a la propuesta de la RAE en cuanto a la substitución de la $x$ por la $s$ antes de consonante $^{23}$.

El texto critica aún de forma indistinta y genérica a los que defienden excesos de simplificación ortográfica sin tener en cuenta más que un criterio foneticista ${ }^{24}$.

Ciertas referencias imprecisas, aunque no permiten identificar las fuentes en concreto, dejan pistas suficientes como para que el público de entonces pudiera identificar la obra en cuestión y a su autor. Ese parece ser el caso de la obra Educação de Almeida Garrett (Londres 1829), la cual, no obstante no ser una obra de lingüística, viene referida en un comentario respecto de la importación lexical ${ }^{25}$. Otras, sin embargo, sólo permiten sacar conclusiones respecto de las ideas lingüísticas y de su filiación - de ello se tratará a continuación.

12 En un comentario respecto del metalenguaje relativo a los modos y tiempos verbales, resalta una referencia indeterminada "a los gramáticos españoles». Su principal interés reside en la asunción de una perspectiva contrastiva y, a la vez, en la exposición del conocimiento de la tradición gramatical española por parte de los gramáticos portugueses $^{26}$. Contrastando los discursos gramaticales en portugués y español con relación al modo de designar formas terminadas en -ria, la gramática editada por Peixoto identifica las designaciones ' $2^{\mathrm{a}}$ terminación de imperfecto de subjuntivo' o ' 2 ' imperfecto de subjuntivo' y 'condicional', respectivamente, con la tradición española y portuguesa. Efectivamente, ésta es la opción terminológica de la GRAE (1796) o de José de Urcullu (1848). Por otra parte, hay gramáticos portugueses de relieve como António José dos Reis Lobato (1807), José Vicente Gomes de Moura (1821) y Jerónimo Soares Barbosa (1822), que, no obstante la adopción de la designación 'condicional', integran estas formas en el modo indicativo.

13 En otros casos, aunque no exista una referencia de cualquier tipo, no deja de ser posible rastrear la huella de una tradición anterior en las ideas lingüísticas expresadas en la obra. Teniendo en cuenta la clasificación de Sánchez Pérez (1992) de las gramáticas decimonónicas para extranjeros en "gramáticas prácticas» y "gramáticas explicativas ${ }^{27}$, hemos de integrar la Grammatica editada por Peixoto en las de corte explicativo, como ya ha puesto en relieve Rogelio Ponce de León (2007 : 64) situando esta obra en la huella de gramáticas como la Nouvelle grammaire espagnolle expliquée en François (Bruxelas 1697) de Francisco Sobrino.

14 Esto queda demostrado, por ejemplo, en la preocupación por el plano conceptual, como ocurre en cuanto a la definición de 'Gramática' : "é a arte, que ensina a fallar, e escrever qualquer lingua correctamente »(Peixoto $1848: 9$ ). Esta definición remonta a Diomedes ${ }^{28}$ y, como observa José Jesús Gómez Asencio (1981 : 18), se incorporó a la tradición cultural europea llegándo incluso a perderse la noción de su autor. El rasgo de originalidad que aparece en Peixoto reside en cuestiones relacionadas bien con su enfoque didáctico («que ensina »), bien con los supuestos teóricos de la gramática general (« qualquer lingua »).

15 A su vez, la división de la Gramática en cuatro partes (ortoepía y prosódia, morfología, sintaxis y ortografía), como demuestra también Gómez Asencio (1981 : 33-41) es la que predomina en las gramáticas españolas del último cuarto del siglo XVIII y de la primera mitad del siglo XIX ${ }^{29}$. Una de las conclusiones posibles, como observa Ponce de León (2006a) es que tratar la ortología previamente a la ortografía podrá indicar, una orientación metodológica hacia la oralidad, lo que este investigador remonta una vez más a la gramática de Sobrino. Con relación al planteamiento de la morfología y la 
sintaxis, resalta el desequilibrio en la extensión de los apartados correspondientes. En efecto, Ponce de León (2006b : 12-14), comentando la atención dedicada a la sintaxis en la tradición gramatical portuguesa, ya ha subrayado que, si bien la sintaxis, en la gramaticografía latina renacentista, es « el objeto preferido de la reflexión teórica por parte de los gramáticos más avanzados » $(2006 b: 12)^{30}$, eso ya no ocurre en la tradición gramatical vernácula.

Respecto de la ortoepía y prosodia, en lo que atañe a la clasificación de las vocales en Peixoto, destaca la noción de que presentan igual sonido en español y portugués (1848: 10). Esta idea la encontramos anteriormente en Moura (1821:5), donde solamente hay puntualización respecto de la letra $u$ cuando después de $g$ y $q u$ aparece con diéresis. Es curioso observar que en los materiales para el aprendizaje del español anteriores a estos trabajos (es decir, las obras de Bluteau (1721) y Howell (1662) anteriormente referidas), el enfoque va orientado al contraste lexical y a la facilitación de la comprensión lectora (de forma explícita en el caso de Bluteau), por lo cual hay un vacío respecto de este tema. En cuanto a la clasificación de las consonantes, la Gramática amplía las notas contrastivas de José Gomes de Moura, con la referencia al sonido que asume la $c$ antes de $e$ o $i$, o con la distinción en la interdental sorda entre sonido 'brando' y 'áspero'. Esta última distinción aparece ya en José de Urcullu (1848:19), a propósito de la pronunciación del grupo consonántico th. La gramática editada por Peixoto también amplía la aportación de Moura en lo que concierne a la consideración de $n$ associada a $h, o$ en la referencia a la indiferenciación articulatoria entre la $v$ y la $b$. En lo que atañe a la articulación de la fricativa bilabial sonora parece haber igualmente antecedentes en Urcullu (1848: 13).

En cuanto a las clases de palabras, cabe avanzar con la integración de esta gramática en un sistema de nueve categorías - artículo, sustantivo, adjetivo, pronombre, verbo, adverbio, preposición, conjunción e interjección. Al no diferenciar el participio como clase independiente del verbo y separando el adjectivo del nombre, esta obra se distancia de la propuesta de la GRAE (1796), presentada por Gómez Asencio (1981 : 97) como la más extendida en la gramaticografía española de entre finales del siglo XVIII y la primera mitad del siguiente.

En conformidad con lo dicho, destaca la referencia a la polémica en cuanto a la consideración del artículo como categoría autónoma (tesis asumida en la obra en estudio) o perteneciente al adjetivo ${ }^{31}$. Aunque ésta es la opinión que Gómez Asencio (1981 : 154) cree estar más extendida, el mismo investigador señala la disidencia de González de Valdés, Francisco Lacueva y Martínez López. Centrando nuestra atención sobre la producción gramatical portuguesa de entonces, en esta obra editada por Peixoto, las propuestas teóricas respecto del artículo difieren de las de Barbosa (1822) y Moura (1854[1829]), y van fundamentadas tanto por razones de orden lógico-semántico como sintáctico. Como señala Gómez Asencio (1981: 155), a pesar del recurso a criterios formales alcanzar poco relieve en la tradición gramatical anterior a la Gramática castellana (Buenos Aires 1847) de Andrés Bello, en cuanto al artículo, hay una excepción. Se ha también de observar aquí la distinción entre artículo y pronombre, por recurso a critérios sintácticos ${ }^{32}$. Según Gómez Asencio (1981 : 171), el reconocimiento del pronombre como clase autónoma remonta a Juan de Miranda ${ }^{33} \mathrm{y}$, en el corpus estudiado por el investigador, sólo Martínez López discrepa. Asimismo, la gramática en estudio, por la alusión al carácter vicario y deíctico ${ }^{34}$, asume un marco convencional en cuanto a la definición de pronombre. Otro aspecto observable en la teoría pronominal de la obra 
es la aplicabilidad del concepto de caso a esta categoría ${ }^{35}$. Esto sí que ya parece indicar una ruptura con la tradición española más conservadora. En este ámbito, cabe subrayar por último que la obra editada por Peixoto se posiciona en contra de la subdivisión de esta categoría ${ }^{36}$.

Sobre la teoría verbal, importa sacar conclusiones tanto de la definición, como de la tipología asumidas. Relativamente a la definición ${ }^{37}$, importa subrayar que se basa en criterios predominantemente morfológicos y que coincide, en cuanto a los accidentes verbales - número, tiempo, persona y modo - , con los que presentan, entre los autores ya citados, los que siguen el mismo tipo de criterio. Sin embargo, amplía esos accidentes considerando también la acepción, la especie, la figura, la voz, la conjugación, y la regularidad. En cuanto a la tipología, parecen coincidir aquí una clasificación en función del significado y una en función de la conjugación. $\mathrm{E}^{\text {ste }}$ criterio lo identifica Gómez Asencio (1985 : 107-108) en Vicente Salvá, pero con diferencias. En la obra, por una parte, la distinción se establece entre verbo substantivo y verbo adjectivo, teniendo en cuentaque el verbo adjetivo se subdivide, por su turno, en verbo activo, neutro, recíproco, reflexivo, auxiliar y pasivo. Por otra parte se distingue etre verbo unipersonal, regular, irregular, y defectivo. Aunque hasta finales del siglo XVIII, ésta terminología estaba connotada con el pensamiento gramatical de Francisco Sánchez de las Brozas, a partir de esta época, el recurso a este metalenguaje se extiende, como demuestra Gómez Asencio (1985 : 115-127), para quien la RAE es una excepción en cuanto a ello. La propuesta de tipología verbal de la obra editada por Nicolau Peixoto parece algo conservadora, pero más bien por su planteamiento predominantemente semántico. Otro aspecto que importa referir en el marco de la teoría verbal es la omisión de un comentario contrastivo sobre el infinitivo personal en portugués ${ }^{38}$.

En lo que atañe a la sintaxis, se presenta la construcción como uno de sus apartados, junto con el régimen y la concordancia ${ }^{39}$, sin profundizar, sin embargo, en la polémica en torno a la relación sintaxis / construcción. Como pone de manifiesto José Jesús Gómez Asencio (1981 : 43-44), la identificación y confusión entre ambos conceptos era habitual tanto en la tradición gramtical española como en la europea, pese a que un conjunto significativo de gramáticos sostiene que hay que diferenciarlos.

21 Respecto de las fuentes de los apéndices de la Grammatica, las únicas menciones explícitas aparecen dentro de lo que es el texto gramatical, y corresponden a las anteriormente referidas. Si se parte del supuesto de que su autor es el mismo ${ }^{40}$, también las fuentes podrán coincidir. Cabe resaltar de nuevo y por los mismos motivos la referencia a Urcullu, quien, en la edición de 1848, también complementa el texto gramatical con material lexicográfico, aunque ese es un rasgo común en las gramáticas de lengua extranjera y aunque, en un primer análisis, no hay indicios de un calco de la obra de Urcullu por parte de José Peixoto.

\section{Conclusiones}

Como síntesis, sería conveniente recordar a grandes rasgos el tipo de obras que están o pueden estar entre sus fuentes. En efecto, la obra en estudio tiende a la filiación dentro de un grupo de gramáticas más tradicional, si consideramos la definición de Gramática, el planteamiento de las diferentes clases de palabras y de su grado de autonomía, la tipología verbal y la teoría sintáctica. Ya en el plano de la ortografía, observamos una actitud modernizadora. Hemos de notar desde ese punto de vista una actitud eclética en 
la conciliación de fuentes más conservadoras (como el discurso académico y la herencia clásica) con autores menos 'ortodoxos' (como José de Urcullu).

\section{BIBLIOGRAFÍA}

ÁLVAREZ, Eloísa. (2005). « Decadencia de la lengua española, primeras gramáticas para lusohablantes y comienzos de la enseñanza de esta literatura en la Universidad de Coimbra », in Luís Filipe Teixeira, Maria José Salema e Ana Clara Santos (orgs.), O livro no ensino das Línguase Literaturas Modernas em Portugal : do Século XVIII ao final da Primeira República. Actas do II Colóquio da A.P.H.E.L.L.E..Coimbra, A.P.H.E.L.L.E., 39-56.

BARBOSA, Jerónimo Soares. (2005 [1822]). Gramática Filosófica da língua Portuguesa. Edição anastática, comentário e notas críticas de Amadeu Torres, Braga, Faculdade de Filosofia Universidade Católica Portuguesa.

CARDOSO, Simão Cerveira. (1994). Historiografia Gramatical (1500-1920). Língua Portuguesa - Autores Portugueses, Porto, Faculdade de Letras da Universidade do Porto.

CARVALHO, Rómulo de. (1986). História do Ensino em Portugal. Desde a Fundação da nacionalidade até o fim do regime de Salazar-Caetano. Lisboa, Fundação Calouste Gulbenkian.

O DEFENSOR Diário (17, 18 e 19 de Agosto de 1848). Porto, Typographia Commercial.

DUARTE, Sónia. (2005). « A aproximação contrastiva ao Espanhol nas Taboas de José Vicente Gomes de Moura : a teoria sintáctica subjacente », in Joaquim Barbosa e Fátima Oliveira (orgs.), Textos seleccionados do XXI Encontro da Associação Portuguesa de Linguística (Porto, 28-30 de Setembro de 2005). Lisboa, Associação Portuguesa de Linguística / Colibri, 329-339.

------(2008a). « O contributo de Nicolau Peixoto para o ensino do Espanhol em Portugal : edição crítica da Grammatica Hespanhola para uso dos portuguezes ».Tese de Mestrado, Departamento de Linguística e Literaturas, Universidade de Évora.

-----(2008b). « Los apéndices de la Grammatica hespanhola para uso dos portuguezes de Nicolau Peixoto : el apartado 'Phrases familiares' ». Boletín de la Sociedad Española de HistoriografíaLingüística $6: 29-46$.

------(en prensa). « Of the Portugues language or subdialect (1662) : a consideração do Português como dialecto do Castelhano na obra gramatical de James Howel ». Diacrítica, Braga, Universidade do Minho.

ESCAVY ZAMORA, Ricardo. (2002). « Aspectos de la aportación hispánica a la teoría general del pronombre ». In Ideas lingüísticas hispánicas : de San Isidoro a Ortega, Murcia, Universidad deMurcia, 21-36.

ESTEVE SERRANO, Abraham. (2007). « Contribución al estudio de las ideas ortográficas en España ». Tonos digital : Revista electrónica de estudios filológicos. nº 13 [documento electrónico disponible en : http://tinyurl.com/n8tar2].

FONTE, Barroso da (coord.). (1998). Dicionário dos mais ilustres Transmontanos e Alto Durienses. Guimarães : Editora cidade do Berço. 
GARCIA PERES, Domingo. (1890). Catálogo razonado biográfico y bibliográfico de los autores portugueses que escribieron en castellano, Madrid, Imprenta del Colegio Nacional de Sordo-Mudos y de Ciegos [documento electrónico disponible en : http ://purl.pt/244 ].

GÓMEZ ASENCIO, José Jesús. (1981). Gramática y categorías verbales en la tradición Española (1771-1847). Salamanca : Ediciones Universidad de Salamanca.

GONÇALVES, Maria Filomena. (2003). As ideias Ortográficas em Portugal - de Madureira Feijó a Gonçalves Viana (1734-1911). Braga, Fundação Calouste / Gulbenkian Fundação para a Ciência e Tecnologia.

KEMMLER, Rolf. (1997). « Ensino da Ortografia cursos de Língua e Discussão de Normas no Portugal dos séculos XVIII/XIX : a Academia Orthográfica Portugueza ». Anais da UTAD : Revista de Letras, 7, 1, Vila Real, Universidade de Trás os Montes e Alto Douro, 13-34.

------(2001). « Para uma História da Ortografia Portuguesa : o texto metaortográfico e a sua periodizacão do século XVI até à reforma ortográfica de 1911 ». Lusorama. Revista de estudos sobre os países de língua portuguesa 47-48:128-319.

LOBATO, António José dos Reis. (1848). Arte da gramática da língua portuguesa. Lisboa, Typ. de José Baptista Morando.

MESSNER, Dieter. (2003). « La lexicografía bilingüe portugués español ». Conferencia presentada al Congreso de la Unión Latina, San Milán de la Cogolla, octubre de 2003, inédita [documento electrónico].

MOURA, José Vicente Gomes de. (1821). Taboas de Declinação e Conjugação para apprender as Linguas Hespanhola, Italiana e Francesa comparando-as com a Portugueza.Coimbra, Imprensa da Universidade.

------(1854[1829]). Compendio de grammatica latina e portugueza : approvado pela resolução de sua Magestade, de 23 de Janeiro de 1829.Coimbra, Real Imprensa da Universidade.

PEIXOTO, Nicolau António (ed.). (1848). Grammatica Hespanhola para uso dos portuguezes, dada á luz por Nicolau António Peixoto. Porto, Typ. Commercial.

PEIXOTO, José Maria Borges da Costa. (1858). Grammatica Hespanhola para uso dos portuguezes, segunda edição correcta e muito aumentada, contendo no fim um vocabulário portuguez-hespanhol das palavras mais usuaes e necessárias. Lisboa, Typ. de Maria da Madre de Deus.

------(1860). Guia da Conversação Hespanhola para uso dos portugueses contendo regras da pronúncia, e acentuação das palavras ; um vocabulario, phrases, e diálogos familiares ; modelos epistolares ; e uma táboa comparativa no valor das moedas hespanholas e portuguezas, colligida dos melhores auctores e ordenada por José M. B. Da Costa Peixoto, auctor da Grammatica Hespanhola, obra util para aprender o hespanhol e para os viajantes á qual se ajuntou, no fim, uma collecção de locuções hespanholas, etc. por outro auctor. Lisboa, Typ. de Maria da Madre de Deus.

PONCE DE LEÓN, Rogelio. (2005). « Textos para la enseñanza-aprendizaje del español en Portugal durante el siglo XIX : una breve historia », in Actas delXV Congreso Internacional de ASELE. Sevilla, Facultad de Filología de la Universidad de Sevilha, 675-682.

----- (2006a). « La gramática y el léxico en la enseñanza del español en Portugal durante el siglo XIX ». Conferência proferida no Fachbereich Romanistik, Universität Salzburg, 17 de mayo de 2006, Inédita [documento electrónico].

----- (2006b). « Un capítulo de la historia de las ideas sintácticas en Portugal : en torno a la teoría sintáctica del Ars grammatica pro lingua lusitana addiscenda (Lyon, 1672) de Bento Pereira (S. I.) ». Forma y función 19 : 11-30. 
------(2007). « Materiales para la enseñanza del español en Portugal y para la enseñanza del portugués en España : gramáticas, manuales, guías de conversación (1850-1950) ». In G. Magalhães (coord.) : Actas do Congresso RELIPES III, Covilhã/Salamanca, UBI/Celya, 59-86.

------(en prensa). « Comparativismo y enseñanza de lenguas en el Portugal del siglo XIX : en torno a las Taboas de declinação e conjugação de José Vicente Gomes de Moura ». InActas del VI Congreso Internacional de la Sociedad Española de Historiografía Lingüística (06-09/11/07), Cádiz, Universidad de Cádiz [documento electrónico].

PONCE DE LEÓN, Rogelio y DUARTE, Sónia. (2005). « O contributo da obra lexicográfica de Bluteau para a história do ensino do Português como língua estrangeira : oMethodo breve, y facil para entender Castellanos la lengua portuguesa ». Revista da Faculdade de Letras. Série « Línguas e Literaturas » $22: 373-429$.

REAL Academia Española.(1796). Gramáticade la lengua castellana. Madrid : Viuda de Don Joaquín Ibarra.

------(1826). Ortografía de la lengua castellana. Madrid : Imp. Real.

------(1845). Prontuario de ortografía de la lengua castellana / dispuesto de Real Orden para el uso de las escuelas públicas por la Real Academia Española con arreglo al sistema adoptado en la novena edición de su diccionario. Madrid : Imp. Nacional.

SALAS, Pilar. (2003). « Los comienzos de la lexicografía bilingüe con el portugués y el español. El Diccionario castellano, y portuguez de Raphael Bluteau ». Res Diachronicae virtual $2: 343-351$ [documento electrónico disponible en :

http ://home.pages.at/resdi/Numeros/Numero2/Parte1_Art38.pdf ].

------(2005a). « Los inicios de la enseñanza de la lengua española en Portugal ». In M. A. Castillo, O. Cruz, J. M. García y J. P. Mora (coords.), Las gramáticas y los diccionarios en la enseñanza del español como segunda lengua : deseo y realidad: Actas del XV Congreso Internacional de ASELE, 799-804.

------(2005b). « Dos pequeños vocabularios de José Maria Borges da Costa Peixoto como testimonio de la lexicografía hispano-portuguesa del siglo XIX ». InDiccionario y Traducción, Málaga, Universidad de Málaga [documento electrónico].

------(2007). « Comentario lexicográfico de la Tabla de palabras portuguezas remotas de la lengua castellana (1721), de Raphael Bluteau ». In C. Pérez-Cordón e J. L. Rámirez (eds.) : El español en sus textos. Manual de comentarios lingüisticos e historiográficos. Lugo : Axac, 109-125.

SÁNCHEZ PÉREZ, Aquilino. (1992). Historia de la enseñanza del español como lengua extranjera. Madrid : Sociedad General Española de Librería.

SARMIENTO, Ramón. (1996). « Historia, problemas y función de una partezilla de nuestra lengua ». In Manuel Casado Velarde et alii (ed.), Scripta Philologica in memoriam Manuel Taboada Cid., Tomo I, Corunha : Servicio de Publicaciones Universidade da Coruña, 209-235.

SILVA, António de Morais. (1789). Diccionario da lingua portugueza composto pelo padre D. Rafael Bluteau / reformado, e accrescentado por Antonio de Moraes Silva natural do Rio de Janeiro. Lisboa : Officina de Simão Thaddeo Ferreira.

SILVA, Inocêncio Francisco da \& e ARANHA, P.V. Brito. (2001 [1858-1923]). Diccionario bibliographico portuguez. col. Bibblioteca Virtual dos Descobrimentos Portugueses, 9, Lisboa, Comissão Nacional para as Comemorações dos Descobrimentos Portugueses [documento electrónico]. 
URCULLU, José de. (1830). Grammatica Ingleza para uso dos Portuguezes reduzida a vinte e cinco lições. Lisboa : Impressão Regia.

------(1848). Grammatica Ingleza para uso dos Portuguezes. Porto : Typ. Commercial.

\section{NOTAS}

1. Se agradece a Dieter Messner la cedencia - en al ámbito de otro trabajo (Ponce de León y Duarte 2005) - de su estudio inédito .

2. Se agradece a Rogelio Ponce de León la cedencia de su estudio inédito.

3. Se trata de Porta de Linguas de Amaro de Roboredo (Lisboa 1623), Prosodia in uocabularium trilingue latinum, lusitanicum et castellanicum de Bento Pereira (Lisboa 1634) y el Diccionario castellano y portuguez de Rafael Bluteau (Lisboa 1721). Hay que resaltar la inclusión, entre los textos preliminares del Diccionario de Bluteau de un opúsculo intitulado Methodo breve, y facil para entender Castellanos la lengua portuguesa. No obstante publicado fuera de Portugal, hay un texto de índole gramatical que precede al de Bluteau y que presenta con su Methodo similitudes significativas, tanto en la forma como en el enfoque. Se trata de of the Portuguese language or subdialect, \&c. del galés James Howell y que éste incluye en su gramática española (Londres 1662). La similitud entre los dos textos consiste en el enfoque contrastivo (portugués / español) asumido en un texto de corta extensión, que discurre sobre las regularidades lexicales entre los dos idiomas y complementado por un glosario de palabras que escapan a las susodichas regularidades. A los aspectos que, por outra parte, separan los dos textos se alude en grandes rasgos en Ponce de León y Duarte (2005 : 382-383). Específicamente sobre la relación entre el Portugués y el Español en la gramática de Howell se ha tratado en otro lugar Duarte (en prensaa).

4. Su relieve ya se ha puesto de manifiesto en otros estudios especificamente sobre esta obra (Duarte 2005; Salas 2007; Ponce de León (en prensa). Se agradece a Rogelio Ponce de León la cedencia de su trabajo aún no publicado.

5. Se agradecen a Ana María Martín y a Rogelio Ponce de León los comentarios aportados en el marco de la preparación / redacción de este estudio.

6. En un primer momento, Inocêncio Silva (2001[1858-1923] tomo V : 24) también indica Oporto como lugar de nacimiento de José Peixoto, pero corrige esa información en el tomo XIII.

7. Para este estudio se han consultado un ejemplar de la edición de 1848, del que es propietaria la autora, y un ejemplar de la edición de 1858, conservado en la Biblioteca Pública Municipal de Oporto, signatura X3-9-148. Todas las citas provienen de la edición crítica publicada por la autora (Duarte 2008a).

8. «De que será, que ninguem até agora se désse ao trabalho de beneficiar a Nação portugueza com um methodo de aprender esta rica e bella lingua?» (Peixoto $1848:<3>$ ). Esta tesis figura también en uno de los catálogos bibliográficos ochocentistas anteriormente citados:

Conociendo á fondo la lengua castellana, y apreciando la conveniencia y necesidad, de que fuese tan familiar, como antes lo había sido, de sus compatriotas, pusieron por obra lo que si otros habian intentado, no llevaron á término, que fue el de proporcionarles los medios para que pudiesen conseguirlo (Garcia Peres 1890 : 465).

9. En el prólogo, aunque no se mencione una relación directa con la obra en estudio, se nombran también a variados autores que tal vez hayan integrado un corpus de referencia para la obra en estudio.

[...] Um BOSCAN, Um GARCILASO, um MONTEMAYOR, Um MENDOZA, Um HERRERA, Um GRANADA, um MARIANA, um PONCE DE LEON, Um CERVANTES, Um LOPE DE VEGA, um VILLEGAS, e outro sem numero de genios sublimes e escritores elegantes e graciosos [...] (Peixoto $1848: 6$ ). 
10. La cita ocurre en el marco de la discusión sobre la declinación : "Este [el principio de la no consideración de la declinación como propriedad de los substantivos] é já um principio inconcusso entre os bons grammaticos [la cursiva es mía], e quem quizer informar-se da demonstração, pode ler o art. Cas da Encyclopedia" (Peixoto $1848: 18$, n.1).

11. Asimismo, se sabe que Peixoto conocía también la existencia de una versión orientada hacia los hispanohablantes -Grammatica Ingleza para uso dos Hespanhoes (Oporto 1840), pues ella va referida por su autor en la edición de 1848 de la gramática inglesa. Peixoto tenía también noticia de otras ediciones fuera de Portugal pues a ellas hay referencia en un documento oficial incluido por Urcullu en la edición de Oporto de 1848 : «Extractos do parecer que deo a Terceira Secção do Ministerio de Commercio, Instrucção e Obras Publicas ao Conselho de Instrucção publica acerca do merecimento da Grammatica Ingleza para uso dos Hespanhoes, por D. Joze de Urcullu, comparada com a do Presbitero D. Joaquim Faria e Camargo » (1848 : VIII-X).

12. «No Diccionario da lingua Portugueza, de Moraes, edição de 1789, está a palavra Madamoesella, tomada do francez, mas por ninguem usada, que eu saiba » (Peixoto 1848 : 30, n.1).

13. "Alguns destes numeraes ordinaes admittem outra terminação em eno. No Diccionario da Academia de Madrid achão-seos seguintes : cinqueno (ant.), seteno, noveno, diceno, onceno, doceno, treceno, catorceno, quinceno, dieziseiseno (ant.), dieziocheno (ant.), veinteno (ant.), treinteno, cuarenteno (ant.), cincuenteno. Porem são muito pouco usados » (Peixoto $1848: 38$ ).

14. Hay opiniones distintas en cuanto al papel de GRAE en la edición de materiales para la enseñanza y el aprendizaje del español en Portugal. Eloísa Álvarez (2005 : 44-45) sostiene que esta gramática se convierte en un modelo para los gramáticos portugueses y que su publicación está intimamente asociada al inicio de la producción de materiales en este ámbito. Por su turno, Rogelio Ponce de León manifiesta cierta reserva en cuanto a esta tesis, ya que, por ejemplo, las Taboas de Moura (1821), como pone de manifiesto el investigador, no siguen el paradigma teórico o metodológico de la RAE. Eso no obsta a que « la influencia de la GRAE ha sido suficientemente probada por Barbara Shäfer-Priess para la gramaticografía del portugués de finales del siglo XVIII y comienzos del XIX » (Ponce de León 2006a).

15. «A Academia de Madrid reprova este costume; porem está tão estabelecido, que não se olha como uma falta, especialmente quando se refere a substantivos, que significão sêres inanimados : e mesmo a harmonia exige este uso para evitar a repetição de sons iguaes. Ex. se lo he entregado : obtuvo el primer premio, no lo merece. Seria aspero dizer : se le he entregado, no le merece " (Peixoto $1848: 42)$.

16. «A estas excepções dadas pela Academia, deve ajuntar-se o substantivo té (chá) para distingui-lode te pronome pessoal » (Peixoto $1848: 128$ ).

17. «Este verbo não se acha marcado como defectivo pela Academia; porem nunca se emprega nos tempos e pessoas que soffrem a irregularidade da 2..$^{\text {a }}$ classe » (Peixoto $1848: 100$ ).

18. «As ultimas reformas introduzidas na lingua hespanhola, autorisadas pela Academia de Madrid e adoptadas por todos os litteratos, aproximando cada vez mais a pronunciação á escriptura, e simplificando sobremaneira esta, tem diminuido as difficuldades da ortografia hespanhola. A Academia nesta reforma excluío de algumas palavras certas lettras, que causavão confusão » (Peixoto $1848: 120)$.

19. «E a etymologia? o pequeno numero de litteratos nunca a ignorará : e a massa do povo, que aprende a ler, e a escrever por necessidade, pouco se embaraça da etymologia, que só serve para augmentar as difficuldades dos que aprendem, e dos que ensinão. Que serviço tão grande faria á Nação a Academia Real das Sciencias de Lisboa, se publicasse uma Grammatica Portugueza, acompanhada d'um tratado de orthografia, em que se prescindisse da etymologia! » (Urcullu 1848 apud Peixoto1848 : 121).

« Em confirmação do que digo em ultimo lugar porei um exemplo entre mil que poderia citar. 
Dizem a um rapaz, ou a um estrangeiro[la cursiva es mía], que não deve pronunciar o $u$ depois de $q$, como em que, quente, aqui, etc.; e logo vem para atormentar a sua memoria as palavras quando, frequencia, tranquillo, nas quaes tem que pronunciar o $u »$ (Peixoto $1848: 121$ ).

20. «Os principios,que podem servir de norma para ser perfeito na escrita pelo que respeita ao uso da lettras, são tres : a pronunciação, o uso constante, $e$ a origem.

A pronunciação serve de norma quando o som d'umalettra não pode equivocar-se com o d'outra. 0 uso serve quando é commum e constante em escrever as palavras com as mesmas lettras. A origem serve de norma quando a pronunciação não determine com que lettra se deve escrever a palavra, o uso não seja constante, e a origem seja conhecida » (Peixoto $1848: 122$ ).

21. "Que serviço tão grande faria á Nação a Academia Real das Sciencias de Lisboa, se publicasse uma Grammatica Portugueza, acompanhada d'um tratado de orthografia, em que se prescindisse da etymologia! O acerrimo etymologista Madureira não se vê muitas vezes obrigado a ceder ao uso, que tem podido mais que a etymologia? Por outra parte os escritores modernos portuguezes vão pouco a pouco perdendo o respeito a esta palavra ; e no cahos e confusão que agora reina por falta d'um systema racional d'orthografia, o tratado que désse a Academia Real, servirira não somente para pôr fim ao scisma, que divide os litteratos portuguezes; mas tambem facilitaria muitissimo nas escolas o ensino da mocidade » (Urcullu 1848 apud Peixoto' 1848 : 121).

22. Podemos encontrar más información al respecto en Filomena Gonçalves, 2003 y Rolf Kemmler 1997, 2001).

23. «Muitos litteratos reclamão contra esta innovação, para que ao menos não se lhe dê toda a extensão, que comprehende a regra. Com effeito é toleravel escrever e pronunciar com $s$ as palavras estrãno, estrangero, estremo, que são as citadas pela Academia : mas n'outras seria esta ortografia insuportavel ; como nas palavras expiar, extinto, expectable, extatica, expatriar, expedir, e muito mais nestas exregente, exrector, exprior, exdiputado, etc. » (Peixoto, 1848 : 125).

24. «Alguns litteratos ainda não assaz satisfeitos com estas reformas, pertendem que se devem abolir inteiramente as lettras $h, q$, e $v$; a primeira como inutil e as outras duas por poderem suprir-se pelo $c$ e pelo $b$.

Porem estas reformas, assim como outras varias pertendidas a este teor, offerecem grandes difficuldades, e em lugar de ganhar a simplicidade ortografica, levada a um tal ponto, desnaturalizaria, e empobreceria a lingua, tirando-lhe um sem numero de differenças nos sons, as quaes são utilissimas para aformosea-la, e dellas os poetas e os oradores sabem tirar grande partido» (Peixoto $1848: 120$ ).

25. « N'uma obra impressa em Londres [1829] sobre Educação, escrita por um sujeito de talento, e que conhece perfeitamente a sua lingua propria tenho visto adoptadas as palavras desappontado e deboché [...] » (Peixoto 1848, 30, n.1).

26. «Alguns grammaticos portuguezes põem no modo condicional a 2..$^{\text {a }}$ terminação do imperfeito do subjunctivo hespanhol, e outros reduzem esse modo ao subjunctivo assim como se usa em hespanhol » (Peixoto 1848, 115).

27. Según este autor, las primeras se basarían en el ejercicio de traducción directa e inversa, aunque, como subraya, no siempre prescindiendo de la teorización.Ya las explicativas insistirían en la descripción gramatical teniendo como modelo a gramáticos españoles sobradamente conocidos por su labor en la difusión del Español en el extranjero, además de la gramaticografía del Español como lengua materna, ámbito en el que resalta la Gramática da Real Academia Española (Madrid 1711).

28. «Gramática es el arte de hablar y escribir correctamente » (apud Gómez Asencio 1981 : 18).

29. Hay que considerar, sin embargo, que el corpus analisado por el autor se circunscribe a las gramáticas del español como lengua materna y que ésta es una obra enfocada hacia el español como lengua extranjera.

30. El autor puntualiza que no se refiere solamente a los partidarios de la gramática filosófica, poniendo a Antonio de Nebrija y a Juan Despauterio como ejemplos entre los partidarios de la 
gramática normativa que tratan exhaustivamente la sintaxis, resaltando a Manuel Álvares entre los gramáticos portugueses que integran a ese grupo.

31. «Os artigos não são verdadeiros adjectivos, como alguns Grammaticos modernos opinão, senão que constituem por si sós uma classe de palavras distincta de todas as outras. 1. Os artigos especificão e individualizão os objectos sem dar a conhecer nenhuma das suas qualidades, e o adjectivo, ao contrario, expressa uma qualidade sem determinar o sujeito em que se acha. 2.ㅇ 0 adjectivo pode ser segundo termo das orações em que entra o verbo substantivo, e o artigo nunca. Diz-se : Pedro es sabio, Pedro é sabio; porem nunca se diz porque nada significa, Pedro es él, Pedro é o» (Peixoto1848: 15).

32. «Não se devem confundir os pronomes pessoaes él, la, lo, los, las, com os artigos el, la, lo, los, las. Os pronomes pessoaes estão sempre juntos a um verbo, ou pronome, e os artigos a um nome » (Peixoto1848 : 41).

33. Para más información sobre los antecedentes de esta cuestión cf. Sarmiento (1996) y Escavy (2002b).

34. "O pronome é uma palavra que se põe em lugar do nome, e que serve para evitar a repetição delle », $\mathrm{y}$ « Os pronomes pessoaes são os que designão mais particularmente as pessoas, ou os que se põem em lugar dellas » (Peixoto1848: 15).

35. «Os pronomes pessoaes são as unicas palavras, que em rigor admittem a declinação, porque varião de terminação, segundo que são o sujeito, regime directo, indirecto, ou o complemento d'uma preposição » (Peixoto $1848: 40$ ).

"Alguns grammaticos designão uma terceira propriedade nos substantivos; a saber : a declinação. Porem consistindo a declinação em exprimir as relações entre as idéas, por meio de certas alterações feitas no material dos nomes; é evidente, que nas linguas em que aquelles não soffrem alteração nenhuma, e as relações se exprimem por meio de palavras separadas, não ha declinação » (Peixoto $1848: 17$ ).

36. « ha um só artigo [...]» (Peixoto $1848: 15)$.

37. «O verbo é uma palavra, cujo uso principal é affirmar com designação do modo, tempo, numero e terminação correspondente á pessoa » (Peixoto $1848: 47$ ).

38. El infinitivo aparece referido en la sección dedicada a los modos verbales : «O infinito exprime a acção d'uma maneira geral e não toma numeros nem pessoas. Este modo é ordinariamente precedido por outro verbo ou por uma preposição » (Peixoto $1848: 49$ ).

39. "A syntaxe é a parte da Grammatica, que ensina a coordenação das palavras, o uso que se deve fazer dellas, as relações que ellas tementre sie o lugar que devem occupar na proposição.

A syntaxe divide-se em tres partes; a saber : Concordancia, Regencia e Construcção » (Peixoto 1848 : 105).

40. Tesis desarrollada ya en Duarte (2008b).

\section{RESÚMENES}

Se procurará rastrear en la Grammatica de Peixoto (1848) la huella de otros textos, enfocando la obra como instrumento de mediación entre idiomas y tradiciones gramaticográficas, como reflejo de la circulación en Portugal de textos metagramaticales, como esfuerzo de comparación entre idiomas sobre los que apenas hay antecedentes bibliográficos de corte contrastivo y, por último, 
como intento de poner término a la rivalidad entre esos idiomas y al déficit bibliográfico que de ella ha resultado.

The essay attempts to reveal the roots of Peixoto's Grammatica (1848), focusing the text as a mean of mediation between languages and gramaticographical traditions, as a reflection of metagrammatical texts' circulation in Portugal, as an effort of comparison between languages on which there is almost no contrastive bibliography, and, at last, as an attempt to put an end to the rivalry between them, which caused the already mentioned bibliographical deficit.

ÍNDICE

Keywords: spanish language teaching, Portugal, XIXth century, Peixoto Nicolau Mots-clés: enseignement de l'espagnol, Portugal, XIXe siècle, Peixoto Nicolau

\section{AUTOR}

\section{SÓNIA DUARTE}

Escola Secundária Dr. Joaquim Gomes Ferreira Alves

Vila Nova de Gaia, Portugal 